\title{
TINJAUAN BENTUK, FUNGSI DAN MAKNA UPACARA MECARU PANYEEB BRAHMA DI DESA BANTIRAN, KECAMATAN PUPUAN, KABUPATEN TABANAN
}

\author{
Ni Nyoman Suastini \\ STKIP Agama Hindu Singaraja \\ Nyomansuastini2018@gmail.com
}

\begin{abstract}
ABSTRAK
Dalam penelitian ini penulis melakukan penelitian yang berjudul: Tinjauan Bentuk, Fungsi dan Makna Upacara Mecaru Panyeeb Brahma di Desa Bantiran, Kecamatan pupuaan, Kabupaten Tabanan. Dengan tujuan sebagai berikut: 1) untuk mengetahui latar belakang dilaksanakannya Mecaru Panyeeb Brahma, 2) untuk mengetahui tata cara/ etika Mecaru Panyeeb Brahma,3) untuk mengetahui Jenis - jenis upakara yang digunakan dalam pelaksanaan Mecaru Panyeeb Brahma, 4) untuk mengetahui fungsi Mecaru Panyeeb Brahma,5) untuk mengetahui Filosofi Mecaru Panyeeb Brahma. Dalam penelitian ini penulis menggunakan metode antara lain: 1) Metode Penentuan Informan, dalam penentuan informan dipakai teknik purposive sampling dan snowball sampling 2) Metode Pengumpulan Data, digunakan teknik wawancara, observasi dan dokumentasi, 3) Metode Analisis Data dengan teknik deskriptif, dan 4)Metode Keabsahan data dengan teknik triangulasi. Dari hasil analisa yang telah dilakukan maka dapat disimpulkan bahwa 1) Latar belakang masyarakat Bantiran melakukan Upacara Mecaru Penyeeb Brahma untuk mengatasi adanya gangguan dari para bhuta kala yang berupa penyakit, hama, dan segala keadaan yang buruk. 2)Tata cara atau etika dalam melaksanakan upacara Mecaru Panyeeb Brahma adalah menggunakan busana adat ke pura, etika berbicara memakai bahasa yang umum digunakan di desa Bantiran yaitu bahasa yang sopan dan dimengerti, tata cara pelaksanaan di awali dengan pemotongan sapi pada siang hari lalu dilanjutkan dengan pelaksanaan Upacara Mecaru Penyeeb Brahma. 3)Jenis - jenis upakaranya yang dipakai di sanggah cucuk: Canang daksina, canang taksu, tipat gong, tegen - tegenan gan gantung - gantungan. Caru karangan terdiri dari sangu apengarangan, lawar pengarangan, jaja apengarangan (cacahan), arepan penganteb. 4) Fungsi pelaksanaan upacara Mecaru Panyeeb Brahma sebagai upaya untuk menciptakan keharmonisan antara manusia dengan para bhuta kala dengan jalan mempersembahkan sesajen berupan banten.5) filosofis dari pelaksanaan Mecaru Panyeeb Brahma adalah cara yang dilakukan masyarakat desa bantiran untuk menetralisir pengaruh panas bumi yang disebabkan oleh para Bhuta kala sehingga masyarakat terhindar dari segala gering (bencana).
\end{abstract}

Kata kunci: Upacara Mecaru Panyeeb Brahma

\section{PENDAHULUAN}

Umat Hindu dalam menjalankan ajaran agamanya berpedoman pada tiga kerangka dasar agama Hindu yaitu Tattwa, Susila, dan Upacara. Aspek tattwa merupakan inti ajaran agama Hindu, sedangkan aspek Susila merupakan pelaksanaan agama dalam kehidupan sehari hari di masyarakat. Aspek Upacara merupakan pengorbanan suci tulus iklas, yajna atau 
persembahan kehadapan Ida Sang Hyang Widhi Wasa- Tuhan Yang Maha Esa.Masyarakat di Bali melakukan berbagai upacara dalam kehidupan beragamanya yang disebut Panca Yadnya. Dewa Yadnya adalah korban suci yang ditujukan kepada para Dewa sebagai manifestasinya, Rsi Yadnya adalah korban suci yang ditujukan kepada para Rsi, Pitra Yadnya adalah korban suci yang ditujukan kepada para leluhur, Manusa Yadnya adalah korban suci yang ditujukan kepada sesama manusia dan Bhuta Yadnya adalah korban suci yang ditujukan kepada para bhuta atau makhluk bawahan.

Dari kelima jenis Yadnya yang disebut di atas, hendaknya dapat dilaksanakan oleh umat Hindu yang dipandang sebagai suatu kewajiban. Tetapi dalam melaksanakan Panca Yadnya ini harus disesuaikan dengan tempat, waktu dan keadaan umat itu sendiri yang dikenal dengan istilah Desa, Kala, Patra . Dari konsep Desa, kala, Patra inilah pelaksanaan upacara agama antara satu dengan yang lain menimbulkan adanya sedikit perbedaan, dan yang lebih menarik lagi adanya suatu keunikan tersendiri, baik dari sisi tradisi kedaerahan yang berlaku maupun pelaksanaan upacara agama.

Seperti yang dijelaskan di atas upacara Bhuta Yadnya adalah pengorbanan suci yang tulus iklas kepada para Bhuta dan kala, yaitu makhluk ciptaan tuhan yang lebih rendah tingkat kedudukan dari pada manusia beserta lingkungan kehidupannya. Para Bhuta dan kala ini mempunyai peranan yang sangat berarti, karena berfungsi sebagai penjaga tempat - tempat tertentu, namun Bhuta kala juga bisa menjadi pengganggu manusia kalau umat manusia tidak menjaga keharmonisan hubungannya.

Fungsi Bhuta kala sebagai pengganggu lebih menonjol. Bhuta dan Kala selalu ingin menghambat manusia yang hendak menghubungkan dirinya dengan Tuhan Yang Maha Esa. Pada dasarnya Bhuta dan Kala ingin menguasai dan mengendalikan manusia. Untuk mengatasi masalah ini, maka manusia perlu memberikan perhatian untuk memuaskan keinginan Bhuta dan Kala tersebut. Agar Bhuta dan Kala tersebut tidak menganggu kita harus memberikan suguhan, sedekah atau sesajen berupa makanan dan minuman yang dinamakan Caru.

Caru yang dibuat biasanya berupa makanan khususnya yang berbau amis, sepeti bawang, jahe, jeroan, darah, nasi dan berbagai minuman yang merangsang. Tingkatan dan bentuk Caru adalah sebagai berikut: Caru tingkat nista; Segehan dan Gelar Sanga, Caru tingkat madya; Eka Sato, Panca Warna, Panca Sato, Panca Sanak, Panca Sanak Madurga, Resighana, Caru tingkat Utama; Panca Kelud, Walik Sumpah, Labuh Gentuh/ Tawur Agung, Tawur Panca Wali Krama, Tawur Eka Dasa Ludra. Pada umumnya Caru tersebut di atas bertujuan untuk mohon kepada Tuhan Yang Maha Esa agar mengadakan pembersihan atau pesucian terhadap lingkungan, seperti pekarangan, perumahan, perkampungan, desa, daerah atau wilayah sampai pada pembersihan bumi dan alam semesta, supaya Bhuta dan Kala atau roh yang jahat tidak mengganggu manusia. Umat Hindu sampai saat ini setiap ada upacara ataupun perayaan hari besar agama seperti Nyepi selalu mengadakan upacara caru tersebut.

Masyarakat desa Bantiran juga melaksanakan upacara Mecaru ini, upacara Mecaru yang dilakukan oleh masyarakat Bantiran ini bernama Upacara Mecaru Panyeeb Brahma. Mecaru Penyeeb Brahma ini dilakukan pada Sasih Kesanga, dilakukan pada Sasih Kesanga karena bulan Kesanga ini dipandang membawa pengaruh, menimbulkan dampak yang negatif. 
Upacara Mecaru Panyeeb Brahma adalah upacara korban yang dilakukan untuk meredakan pengaruh negatif yang timbul pada bulan Kesanga, keunikan yang terdapat dalam pelaksanaan Upacara Mecaru Panyeeb Brahma terletak pada wewalungan (daging) yang digunakan, wewalungan (daging) utama yang digunakan adalah godel (sapi). Selain itu orang yang memotong sapi tersebut juga harus dari keturunan keluarga tertentu yang telah ditentukan sejak dahulu.

Dari uraian tersebut di atas, maka peneliti tertarik untuk mengadakan penelitian tentang pelaksanaan upacara Mecaru Panyeeb Brahma di desa Bantiran, Kecamatan Pupuan, Kabupaten. Rumusan masalah dalam penelitian ini dapat dijabarkan sebagai berikut: (1) Kenapa dilaksanakan Upacara Mecaru Penyeeb Brahma di Desa Bantiran, Kecamatan Pupuan, Kabupaten Tabanan?, (2)Bagaimana tata cara/ etika Upacara Mecaru Penyeeb Brahma dalam kaitanya dengan bhuta yadnya di Desa Bantiran, Kecamatan Pupuan, Kabupaten Tabanan?, 3. Jenis - jenis upakara apa yang digunakan dalam pelaksanaan Upacara Mecaru Penyeeb Brahma dalam kaitanya dengan bhuta yadnya di Desa Bantiran, Kecamatan Pupuan, Kabupaten Tabanan?, 4. Apa fungsi Upacara Mecaru Penyeeb Brahma di Desa Bantiran, Kecamatan Pupuan, Kabupaten Tabanan?, (5)Apakah makna Filosofi Upacara Mecaru Penyeeb Brahma dalam kaitanya dengan bhuta yadnya di Desa Bantiran, Kecamatan Pupuan, Kabupaten Tabanan?.

\section{PEMBAHASAN}

\section{A. Latar Belakang Dilaksanakan Upacara Mecaru Panyeeb Brahma di Desa} Bantiran, Kecamatan Pupuan, Kabupaten Tabanan

Dilaksanakannya Upacara Mecaru Penyeeb Brahma di desa Bantiran menurut Wayan Semerta didasari dengan adanya kuna dresta yang telah diwariskan secara turun temurun oleh masyarakat Bantiran (wawancara, 27 Maret 2020).

Sedangkan menurut Wayan Winata dilaksanakanya caru Panyeeb Brahma yang memakai wewalungan sapi didasari oleh perintah raja Tabanan, karena beliau merasa wilayah desa Bantiran sangat riskan terkena bencana apalagi berbatasan dengan kerajaan Buleleng sehingga harus dilaksanakan caru untuk menetralisir pengaruh pengaruh buruk yang akan ditimbulkan (wawancara, 14 Maret 2020).

Dari pemaparan diatas dapat disimpulkan bahwa tujuan dilaksanakan Upacara Mecaru Penyeeb Brahma adalah untuk menetralisir terjadinya hal - hal buruk yang mungkin terjadi pada masyarakat dan lingkungan di desa Bantiran.

\section{B. Tata Cara atau Etika pada saat Upacara Mecaru Penyeeb Brahma di Desa Bantiran, Kecamatan Pupuan, Kabupaten Tabanan}

Tata cara atau etika masyarakan Bantiran pada saat melaksanakan upacara Caru Panyeeb Brahma, dimulai dari segi berbusana atau berpakaian pada pagi hari dan siang hari saat mempersiapkan banten yang akan digunakan untuk pecaruan dan pada saat melakukan proses pemotongan sapi digunakan pakaian adat madia (atasan baju kaos atau kemeja dan bawahanya memakai kamen dan selendang), dan saat melaksanakan pecaruan masyarakat bantiran memakai baju adat ke pura. Dalam proses pemotongan sapi sampai persembahyangan digunakan bahasa bali umum dan bahasa Bali alus. Dan pada saat persembahyangan antara peserta laki - laki ataupun perempuan duduknya tidak diatur namun semua masyarakat menjaga dan saling menghormati satu sama lain. 
Tahapan kegiatan sangat penting dipahami sebagai acuan dalam menyelenggarakan/ melaksanakan suatu kegiatan.

Sesuai hasil wawancara dengan Wayan Semerta sebagai petajuh desa Bantiran menyebutkan:

a). Pada pagi hari masyarakat Bantiran berkumpul untuk menyiapkan segala hal yang akan dipergunakan dalam upacara mecaru yang akan dilakukan, yang perempuan dibantu oleh saya tahunan (orang yang bertugas membantu proses persiapan upacara hingga pelaksanaan upacara) mempersiapkan banten yang akan dipakai dalam Upacara Mecaru Penyeeb Brahma.

b). Pada saat siang hari tepat pukul 12.00 setelah berbunyi pentongan desa (kulkul), mayarakat kembali berkumpul untuk melakukan penyucian terhadap godel (sapi) dengan diperciki tirta dari pura tri khayangan dan juga tirta dari catus pata. Setelah diperciki tirta godel itu di arak sebanyak tiga kali di jalan, dimulai dari arah selatan/ tanggun desa sampai batas ujung desa/ arah utara. Pada saat sapi melalui satu putaran tepat di catus pata dilukai untuk meneteskan darah sebagai bentuk awal caru, lalu diarak lagi hingga dua kali kembali dilukai, hingga yang ke tiga kalinya sapi dibunuh. Setelah sapi itu dibunuh maka semua komponen sapi tersebut diolah untuk menjadi bahan perlengkapan Upacara Mecaru Penyeeb Brahma. setelah selesai mengolah sapi tersebut masyarakat pulang ke rumah masing - masing.

4. Pada saat sore hari sebelum terbenamnya matahari atau dalam istilah Balinya disebut dengan sandikala masyarakat kembali berkumpul setelah berbunyi pentongan desa (kulkul) di catus pata lalu berjalan menuju sor ring desa, di sor ring desa ini dilakukan Upacara Mecaru Penyeeb Brahma yang pertama, persembahyangan dipimpin oleh jero mangku puseh didampingi jero mangku yang lain, langkah pertama adalah menghidupkan bobok lalu diselipkan di sanggah cucuk sebagai tanda awal dimulainya pecaruan, dimana semua banten sudah di tempatkan pada tempatnya masing - masing. setelah selesai di sor ring desa, masyarakat berjalan menuju madyaning desa (di tengah desa) proses pecaruan sama dengan proses pecaruan yang pertama, dan pecaruan terakhir dilakukan di ulunin desa dengan proses yang sama dengan pecaruan pertama dan kedua.

5. setelah selesai melakukan pecaruan dan persembahyangan bersama, kemudian masyarakat mebuu - buu.

\section{Jenis - Jenis Upakara Yang Digunakan Dalam Pelaksanaan Caru Panyeeb Brahma di Desa bantiran, Kecamatan Pupuan, Kabupaten Tabanan}

Setiap upacara keagamaan baik dalam tingkatan nista, madya, maupun yang utama pastilah memerlukan sarana atau upakara. Suatu upacara agama tidak dapat dilaksanakan tanpa adanya upakara yang menyertainya. Upakara yang dipakai dalam upacara caru Panyeeb Brahma yang dijelaskan oleh

1. Dulun Desa: di sanggah cucuk: Canang daksina, canang taksu, tipat gong, tegen - tegenan gan gantung - gantungan. Caru karangan terdiri dari sangu apengarangan, lawar pengarangan, jaja apengarangan (cacahan), arepan penganteb.

2. Madyaning Desa: di sanggah cucuk: Canang daksina, canang taksu, tipat gong, tegen - tegenan gan gantung - gantungan. Caru karangan terdiri dari sangu apengarangan, lawar pengarangan, jaja apengarangan (cacahan), arepan penganteb. 3. Sor ring Desa: di sanggah cucuk: Canang daksina, canang taksu, tipat gong, tegen - tegenan gan gantung - gantungan. Caru karangan terdiri dari sangu apengarangan, lawar pengarangan, jaja apengarangan (cacahan), arepan penganteb. 


\section{Fungsi Upacara Mecaru Panyeeb Brahma di Desa Bantiran, Kecamatan Pupuan, Kabupaten Tabanan}

Upacara Mecaru Penyeeb Brahma yang dilaksanakan di desa Bantiran memiliki beberapa fungsi yaitu: 1) Fungsi Keagamaan, 2) Fungsi Sosial.

1) Fungsi Keagamaan

a. Sebagai sarana pembersihan/ penyucian bhuana agung dan bhuana alit (alam semesta beserta isinya). Alam semesta ini perlu disucikan dari pengaruh - pengaruh buruk yang ditimbulkan oleh para Bhuta Kala sehingga tercipta suatu keseimbangan dan keharmonisan.

b. Sebagai bhakti persembahan dan tanda terima kasih yang ditujukan kepada Tuhan dengan segala manifestasinya atas kemurahan-Nya telah melimpahkan suatu kehidupan dan alam semesta ini yang merupakan anugrah Tuhan yang paling berharga.

c. Sebagai perwujudan rasa bhakti kepada Tuhan yang telah berkenaan menciptakan alam semesta beserta isinya. Karena penciptaan adalah suatu proses kerja/ karma, oleh karena itu semua pekerjaan harus dilakukan sebagai rasa bhakti dan pengabdian kepada Tuhan.

d. Sebagai media konsentrasi dan komunikasi, karena pada saat Upacara Mecaru Penyeeb Brahma ini dilangsungkan ada berbagai jenis upakara, sebab keberhasilan suatu yadnya tidak terlepas dari berbagai sarana yang digunakan, melalui sarana ini dengan mudah kita menghubungkan diri dengan Tuhan, dan melalui sarana ini pula umat Hindu dapat berkomunikasi dengan yang dipuja.

2. Fungsi Sosial/ Kemasyarakayan

a. Rasa persatuan dalam mencapai cita - cita. Adanya rasa persatuan pada manusia ini dilandasi oleh adanya kepentingan bersama seperti: rasa tentram, rasa aman, perlindungan, dan sebagainya. Dengan melaksanakan Upacara Mecaru Penyeeb Brahma mereka secara bersama - sama mengerjakan upakara yang akan dipersembahkan kehadapan para bhuta kala agar mereka terbebas dari segala macam derita (penyakit) disamping sebagai penyucian tempat.

b. Proses Pendidikan:Upakara/ Banten itu umumnya berbentuk material yang mempunyai nilai seni disamping nilai spiritual yang disebut dengan budaya agama. Hal ini perlu diwariskan kepada generasi penerus. Dalam kaitanya dengan pelaksanaan Upacara Mecaru Penyeeb Brahma di desa Bantiran secara tidak langsung telah terjadi proses pendidikan keagamaan dan pewarisan serta kelestarian terhadap budaya agama ini.

\section{E. Makna Filosofis Upacara Mecaru Penyeeb Brahma di Desa Bantiran, Kecamatan Pupuan, Kabupaten Tabanan}

Penyeeb berasal dari akar kata Seeb yang artinya siram dengan ( api bata dsb); apine apang enggalan mati, siram api itu dengan air supaya lebih cepat mati. Nyeeb Brahma artinya nama upacara korban untuk meredakan pengaruh panas yang jahat. Binatang korban yang dipergunakan pada upacara Mecaru di desa Bantiran adalah seekor godel (sapi). Godel atau sapi adalah jenis binatang peliharaan manusia, yang dapat memberikan manfaat yang cukup besar karena sapi adalah binatang yang sangat bermanfaat bagi kehidupan manusia seperti membajak, menarik gerobak, kotoranya untuk rabuk bahkan air susunya disumbangkan untuk manusia untuk dinikmati. Bukanya hanya itu saja bahkan dirinya dikorbankan demi kerahayuan manusia. 
Sapi dalam mitos Hindu banyak digunakan sebagai simbol alam semesta atau simbol bumi. Bumi yang ditempati oleh manusia, binatang, dan tumbuh - tumbuhan adalah sumber dari harta benda yang dapat memenuhi keinginan atau kama manusia (Wiana, 1993: 2). Oleh karena itulah binatang sapi sering digunakan sebagai sarana upakara dalam yadnya, terutama upacara Bhuta Yadnya. Begitu pula dalam upacara Pitra Yadnya, misalnya pada saat Upacara Ngasti Wedana sapi atau lembu diwujudkan dalam dalam bentuk simbolis yang dibuat menggunakan kayu, kain, kertas dan lain sebagainya berfungsi sebagai tempat tempat pembakaran jenasah. Badan kasar manusia juga terdiri dari unsur - unsur alam semesta dan setelah meninggal unsur unsur itu akan kembali ke asalnya yang diwujudkan dengan lembu. Demikian pula pada saat berlangsungnya upacara Ngatma Wedana dalam tingkatan yang utama kembali lembu melengkapi upacara tersebut. sebelum distanakan di balai payadnyan, sekah terlebih dahulu diusung menginjak banten titi mamah dan mengikuti jalannya lembu (sapi yang bulunya putih) yang telah dihiasi dan disakralkan mengelilingi payadnyan tiga kali yang disebut "purwa daksina" . Banten titi mamah adalah lambang bumi yang dipakai dasar untuk mencapai dunia yang lebih suci. Demikian pula lembu yang mengantarkan atma menuju triloka (Bhur, Bwah, dan Swah) yang dilambangkan bertigkat tiga. Lembu, banteng kerbau, pada hakekatnya adalah binatang sapi (Wiana, 1993:5).

Dalam ajaran Tri Murti sapi diwujudkan dalam bentuk patung lembu Nandini, seperti pada kompleks candi Prambanan di depan Candi Lorojongrang terdapat tiga candi yaitu: Candi Angsa, Candi Nandini, dan Candi Garuda. Candi Nandini tepat berhadapan dengan Candi Siwa. Candi Nandini adalah candi yang berbentuk lembu atau sapi lambang kendaraan Dewa Siwa. Jadi Siwa mempunyai kendaraan khusus yaitu lembu Nandini (Wiana,1993: 3).

Di dalam wisnu purana juga disebutkan bahwa krisna sebagai gopala artinya pelinding sapi. Sri Krisna adalah awatara Tuhan Yang Maha Esa dalam fungsinya sebagai pemelihara dan pelindung alam semesta ini. Sedangkan sapi yang digembalakan oleh Sri Krisna tidak lain daripada lambang alam semesta ini (Wiana,1993: 10).

Demikian pula di dalam Bhasa Bharata dan Aranyaka Parwa dijelaskan bahwa Kamadhenu atau lembu Nandini adalah ibu pertama dari semua ternak. Kamadhenu atau Surabi disebutkan sebagai dewi kekuatan dan kecakapan yang dapat memberikan susu kepada para Dewa dan rsi (Wiana,1993: 6). Dari uraian diatas dapat disimpulkan bahwa Siwa atau Tuhan Yang Maha Esa adalah jiwa alam semesta dan lembu Nandini sebagai wahananya adalah lambang dari alam semesta.

Apabila diperhatikan di dalam pelaksanaan Bhuta Yadnya binatang yang digunakan upakara itu terlebih dahulu dilakukan sakralisasi yang disebut Mepepada yang bertujuan untuk menyucikan jiwatma dari binatang yang akan dipakai upakara. Jadi di sini jiwa dari binatang itulah yang diutamakan diberikan doa berupa mantra - mantra suci tertentu agar binatang yang dipakai sarana upacara itu meningkat kedudukan spiritualnya. Konsep ini tidak melihat binatang itu dari segi fisiknya, tetapi lebih mengutamakan jati dirinya secara spiritual yaitu untuk meningkatkan kwalitas dari binatang itu sendiri bila menjelma di kemudian hari atau kembali pada asalnya.

Jadi makna filosofis Upacara Mecaru Panyeeb Brahma adalah sebagai jalan untuk meredakan panas bumi yang bisa menyebabkan gering (bencana) atau menetralisir hal - hal negatif yang berasal bari Bhuta kala. Bila hal ini dikaitkan dengan penggunaan godel (sapi) dalam Upacara Mecaru Penyeeb Brahma karena sapi itu dianggap binatang yang suci, godel (sapi) adalah lambang bumi atau lama semesta, 
yang dapat memberikan keinginan manusia, dan siwa adalah jiwa alam semesta. Dengan demikian wajarlah sapi (bumi) merupakan kendaraan dewa Siwa dan patutlah manusia mempersembahkan caru kepada beliau sebagai ucapan rasa terima kasih atas segala pengorbanan beliau. Dengan dilaksanakannya Upacara Mecaru Penyeeb Brahma ini, masyarakat percaya bisa terhindar dari segala bencana. (wawancara, 28 Maret 2020).

\section{Kesimpulan}

1. Pelaksanaan upacara Mecaru Penyeeb Brahma di desa Bantiran adalah sebagai usaha untuk menciptakan hubungan yang harmonis antara manusia dengan alam lungkungannya. Yang diwujudkan dengan upacara Bhuta Yadnya.

2. Upacara Mecaru Penyeeb Brahma "pemuwus niskala" yang diyakini kebenaranya dan merupakan perintah suci dari Maha Pencipta, serta telah dilaksanakan secara turun - temurun setiap tahun sekali pada sasih kesanga di sor ring desa, madyaning desa dan ulunin desa.

3. Upacara Mecaru penyeeb brahma ini ditunjukkan pada para Bhuta kala untuk memohon keharmonisan dan agar terbebas dari segala derita yang disebabkan oleh berbagai macam penyakit, sehingga kesejahteraan dapat dicapai.

4. Upacara Mecaru penyeeb brahma ini juga bertujuan membersihkan wilayah at tempat, menetralisir kekuatan/ pengaruh buruk yang ditimbulkan oleh para Bhuta kaid sehingga keseimbangan alam semesta beserta isinya tetap terpelihara dengan baik.

\section{DAFTAR PUSTAKA}

Arikunto, Suharmi. 1998. Prosedur Penelitian Pendekatan Praktek. Yogyakarta Rineka Cipta.

C. Ruddyanto. 2010. Kamus Budaya Bali Bidang istilah Upakara. Denpasar: Balai Bahasa.

Donder, I Ketut. 2007. Kosmologi Hindu. Surabaya: Paramita.

Hadari Nawawi. 2001. Metode Penelitian Bidang Sosial. Jakarta : Gajah Mada University Press.

Ida Pandita Mpu Nabe Parama Manik Dwija Kertha.1999. Puja Mantra Ageman Pemangku/ Pinandita. Buleleng: Gria Taman Bhadrika Asrama.

Koentajaraningrat. 1982. Ritus Peralihan di Indonesia. Jakarta: Balai Pustaka.

Koentajaraningrat. 1990. Pengantar Antropologi. Jilid-1 Jakarta: Rineka Cipta.

Mas Putra, Ny. I.G.A. 1982. Upacara Yadnya. Denpasar: Dinas Agama Hindu dan Bhuda.

Moleong, lexy, J. 1993. Metodelogi Penelitian Kualitatif. Bandung : PT. Remaja Rosdakarya.

Mulyana, Deddy. 2001. Penelitian Kualitatif. Bandung : PT. Remaja Rosdakarya.

Ngurah dkk.1999. Buku Pendidikan Agama Hindu untuk Perguruan Tinggi, Surabaya: Paramita.

Nurkancana, Wayan. 1999. Pokok - Pokok Ajaran Agama Hindu. Denpasar: Manikgeni.

Pasek Swastika, I Ketut.2009. Caru. Denpasar: Kayumas Agung.

Pasek Swastika, I Ketut.2008. Bhuta Yadnya. Denpasar: Pustaka Bali Post.

Pudja, Gede. 1982. Bhagawadgita. Jakarta: Mayasari.

Sri Reshi Anandakusuma. 1986. Kamus Bahasa Bali. Denpasar: CV. Kayumas Agung. Sri Reshi Anandakusuma. 2009. Aum Upacara Bhuta Yadnya. Denpasar: CV. Kayumas Agung. 
Jurnal Widya Sastra Pendidikan Agama Hindu, Vol 4, No. 1, 2021

ISSN: 2656-7466

Suhardana. 2010. Kerangka Dasar Agama Hindu Tattwa, Susila, Upacara, Surabaya: Paramita.

Suprayogo Imam, dan Tabroni. 2001. Metodelogi Penelitian Sosial, Agama. Bandung : PT. Remaja Rosdakarya.

Titib, I Made. 2001. Teologi dan Simbul - Simbul Dalam Agama Hindu. Surabaya: Paramita.

Tri Guna, Ydha. Ida Bagus Gede.2000. Teo 59 ang Simbol. Denpasar: Wisma Karma.

Wiana, Ketut. 2004. Keagungan Sapi Menurut Weda. Denpasar: Manikgeni.

Wiana, I Ketut. 2002. Makna Upacara Yadnya dalam Agama Hindu. Surabaya: Paramita.

.2007. Kala Tattwa Singaraja. Pemerintah Kabupaten Buleleng Dinas Kebudayaan dan Pariwisata UPTD Gedong Kirtya. 